\title{
Laparoscopic Versus Open Appendicectomy - A Randomized Controlled Trial
}

\author{
A ALI ${ }^{\mathrm{a}}$, MAW CHOWDHURY ${ }^{\mathrm{b}}$, HMA ROUF $^{\mathrm{c}}$, OF YUSUF ${ }^{\mathrm{d}}, \mathrm{S} \mathrm{ISLAM}^{\mathrm{e}}$
}

\begin{abstract}
Summary:
Background: The authors compare open and laparoscopic appendicectomy in a randomized fashion with an object to define benefit of laparoscopic procedure if any.
\end{abstract}

Methods: Patients of acute appendicitis were randomized to either laparoscopic $(n=62)$ or open $(n=58)$ appendicectomy . Operation time, per-operative findings, concomitant and or other pathological lesions, postoperative pain, rescue narcotic analgesia required, negative appendicectomy rate, hospital stay and complications were noted.

Results: No patient in the laparoscopic group required conversion to open. The mean operation time were $36.51 \pm 15.81$ minutes and 31.62 \pm 19.61 minutes for the laparoscopic and open groups respectively $(p=0.1368)$. But the operation time is low in LA group (mean $37.92 \pm 16.28$ versus $62.55 \pm 20.04$ minutes, $p=.0080$ ) when only high up retrocaecal types were considered. In the laparoscopic group 45 patients (72.58\%) had acute appendicitis, 15 (24.19\%) had other pathologies (appendix

\section{Introduction:}

Since its introduction by McBurney in 1894, appendectomy has been the treatment of choice for acute appendicitis ${ }^{1}$. Appendicitis is the most common

a. Dr.S.M.Ashraf Ali. FCPS Surgery, Associate Professor of Surgery, Chittagong Medical College.

b. Dr. MA Wahhab Chowdhury. MPhil Pathology, Professor of Pathology, Chittagong Medical College.

c. Dr. HMA Rouf. FCPS Surgery, Professoe of Surgery, Chittagong Medical College.

d. Dr. Omor Faruque Yusuf, FCPS Surgery, FRCS, Professor of Surgery, Chittagong Medical College.

e. Dr. Md. Saiful Islam, FCPS Surgery, RS (Surgery) Chittagong medical College hospital

Address of correspondence: Dr.S.M.Ashraf Ali. FCPS Surgery, Associate Professor of Surgery, Chittagong Medical College.E mail: ashrafa@btcl.net.bd

Received: 14 December, 2008

Accepted: 10 February, 2009 were histologically normal) and in 2(3.225\%) appendix were normal. Post operative pain score was significantly low ( $p=0.037$ ) in LA group after six hours but became insignificant after twelve hours $(p=0.959)$ and twenty fours ( $p=0.114)$. The LA group required significantly less rescue narcotic analgesia $(p=0.026)$. Hospital stay was significantly shorter in the laparoscopic group (29.935 \pm 8.995 versus $35.413 \pm 11.30$ hours, $p=0.0038)$. The wound infection rate is higher in open group $(13.79 \%$ versus $6.45 \%$ )

Patients who underwent LA have a shorter operation time in high-up retrocaecal type of appendicitis, significantly less pain and require less rescue narcotic analgesia in comparison to open operation.

Conclusions: Laparoscopic method offers an excellent opportunity to detect concomitant other pathology and there by reduce incidence of missdiagnosis and negative appendicectomy rate. The authors consider LA to be the procedure of choice in patients with acute appendicitis.

(J Bangladesh Coll Phys Surg 2009; 27: 82-90)

intra-abdominal condition requiring emergency surgery, with a lifetime risk of $6 \%^{2,3}$. For more than a century, open appendicectomy (OA) remained the gold standard for the treatment of acute appendicitis. Unfortunately the diagnosis of acute appendicitis is often difficult, mainly clinical and always challenging. An accepted negative appendicectomy rate for presumed appendicitis ranges from $15 \%$ to $20 \%$, even higher in women of childbearing age $(20 \%$ to $30 \%)^{4,5}$. Attempts were taken to reduce the negative exploration rate by lower abdominal CT scan and Ultrasonography (US) but result were frustrating. The highest positive predictive value for diagnosis of acute appendicitis by CT and US is $83.8 \%$ and $81.3 \%$ respectively ${ }^{6}$. Before the era of laparoscopic surgery single umbilical port diagnostic laparoscopy enabled to diagnose appendicitis as high as in $50 \%$ cases $^{7}$. The advent of endoscopic surgery led to the idea of performing laparoscopic 
appendicectomy (LA). In 1983 Semm, a German Gynecologist performed the first $\mathrm{LA}^{8}$. More than 2 decades later, the benefits of LA are still controversial. Despite numerous case series and randomized clinical trials comparing LA versus OA, a consensus concerning the relative advantages of each procedure has not yet been reached $3,9,10,11$. The goal of the present study is to compare the effectiveness and or benefits of LA over OA based on a simple randomized clinical trial with the hypothesis that LA is beneficial.

\section{Materials and Methods:}

From July 2006 to June 2007, patients between 19 and 49 years diagnosed as acute appendicitis were offered entry into the study. The diagnosis of appendicitis was made if all six set criteria: history of right lower quadrant pain and or periumbilical pain migrating to the right lower quadrant, nausea and/or vomiting, temperature more than $38^{\circ} \mathrm{C}$ and/or leukocytosis above 10,000 cells per $\mathrm{cmm}$, right lower quadrant guarding and or tenderness on physical examination, lower abdominal US diagnostic to appendicitis or normal and normal kidney ureter bladder (KUB) region X-Ray were present. Patients with confirmed or suspected appenducular lump, ASA score III and IV, previous history of lower abdominal surgery was not included in the study. The qualifying patients were informed of the risk and benefits of each operation and asked to sign a detailed informed consent in "Bangla", approved by the institutional review board (IRB). All were informed that oral fluid will be started 6 hours after operation and if tolerated well will be followed by liquid and discharged from the hospital at or after 24 hours if not contraindicated. Baseline parameters were evaluated before randomization once the informed consent was signed. Patients were assigned randomly to receive either open or laparoscopic appendicectomy.

All operation were performed by first author experienced in open surgery ( $>20$ years) and advanced laparoscopic techniques ( $>7$ years). Patients received $200 \mathrm{mg}$ Ciprofloxacine every 12 hours and $500 \mathrm{mg}$ Metronidazole intravenously from the time of diagnosis until oral fluid was well tolerated post-operatively. OA used a McBurney muscle-splitting incision $3-4 \mathrm{~cm}$, and extension as required in the right lower quadrant. The distal ileum was visualized to detect possible Meckel's diverticulitis. The skin incision was closed with 2-0 vicryl either intradermally or transdermal interrupted stitch.

LA was performed using 3 ports, 10-mm umbilical port initially used for telescope. One 5-mm ports inserted in the right lower quadrants and another 5$\mathrm{mm}$ or $10 \mathrm{~mm}$ port in the midline suprapubically according to availability of $5-\mathrm{mm}$ telescope. Telescope shifted to the suprapubic port. The foot end and right side of the OT table was elevated up to $15^{\circ}$. The abdominal cavity was explored to locate the appendix and rule out other possible diagnoses. Position of the appendix, adhesion if any was recorded. In case of adhesion adhesiolysis done using monopolar diathermy hook dissection by taking care to not to injure the gut or other structure. The base of the appendix was doubly ligated with no.1 silk by intracorporeal suture (Fig.2) after creating a window and divided in between. The mesoappendix was ligated by similar fashion or clipped and divided close to the appendix using monopolar diathermy (Fig.3). The right lower quadrant, the right colic gutter and the subhepatic space in the case of purulence were irrigated and the fluid was suctioned. The appendix was removed through umbilical port after taking in side the reducer sheath to avoid contamination or in a self made endo-bag- with sterile hand glove. Facial defects in the port sites were closed using 2-0 Vicryl suture. The skin incisions were closed in every case using 2-0 Vicryl.

In LA operation time was recorded from first port insertion to last port closure in minutes and in $\mathrm{OA}$ from skin incision to skin closure. $50 \mathrm{mg}$ I.V. pethedine and $8 \mathrm{mg}$ Ondansetron ( Onaseron Inj.) was used per-operatively in all cases. At the end of operation just after recovery $50 \mathrm{mg}$ Diclofenac in the form of suppository was used and repeated 8 hourly for 48 hours.

Post-operatively pain was measured following Visual Analogue Scale (VAS) ${ }^{12}$ every 6 hours and when it was $>36 \mathrm{~mm}$ rescue analgesia -in the form of pethedine-75 mg were administered intramuscularly and recorded. Bowel sounds were checked every 6 hours. Once present, the patients were started on a 
clear liquid diet and advanced to regular diet when the liquid diet was tolerated and flatus observed. Patients were discharged when they tolerated a regular diet, had pain score $<24 \mathrm{~mm}$.

All resected specimen of appendix were submitted for histopathology. On discharge all the patients were advised to visit on $4^{\text {th }}$ and $7^{\text {th }}$ post-operative day if not indicated earlier due to pain, vomiting, fever or absolute constipation and any wound complication were recorded.

\section{Statistical Methods}

The sample size was calculated before the beginning of the trial based on an analysis of sample sizes required for each of the main parameters (pain score $40 \pm 15 \mathrm{~mm}^{11}$ and negative exploration rate $\left.25 \% \pm 5.6^{4}\right)$ for $95 \%$ confidence interval $(\alpha=0.05)$ and a power of $80 \%$. to ensure $20 \%$ difference. A sample size of 56 was calculated to be sufficient to detect this difference.

An unpaired student's $t$ test was used for parametric data. Fisher's exact test or the $\chi^{2}$ test was used to compare $2 \mathrm{x}$ 2 contingency tables. Analysis were performed using SPSS version 11.5, Chicago, Illinois, USA, Excelanalyze it 2007 and Graph pad Quick cal 2007.

\section{Results:}

There were 120 patients entered in to the study, 62 in LA group and 58 in OA group. Nine patients excluded from the study because of contraindication to creation of carbon dioxide pneumo-peritoneum. Of these 2 patients were ASA grade IV, 2 patients suffering from COPD, 2 patients with persistent hypertension (systolic $>200 \mathrm{~mm} \mathrm{Hg}$ and diastolic $>110 \mathrm{~mm} \mathrm{Hg}$ ) even on antihypertensive treatment, 3 with previous lower abdominal surgery.

Base line characteristics of patients in both LA and OA group were similar except male female ratio, 19:43/32:26 $\quad(p=0.0058) \quad$ indicating female preponderance (Table I). The mean operative time in LA group was 36.51 minutes; for the OA group, 31.62 minutes $(p=0.136)$ when

considered whole series and it is insignificant. But when the open and laparoscopic groups are divided into subsets based on appendix position, high up retrocecal (HUR) groups and analyzed separately, operation times detected significant (Table II). The HUR appendicitis in LA group required 37.92 minutes for the completion of surgery but it was
62.55 minutes in open group $(\mathrm{p}=0.008$, highly significant). When HUR are excluded mean operation time is longer in LA group (35.57 minute versus 25.94 minutes, $\mathrm{p}=0.0083$ ).

In the open group, 47 patients had acute appendicitis $(81.03 \%), 9(15.56 \%)$ had normal appendix and in $2(3.45 \%)$ other pathology were there, subsequent histopathology also revealed normal appendix. In the laparoscopic group, 45 patients had acute appendicitis $(72.58 \%), 2(3.23 \%)$ had normal appendix and in $15(24.19 \%)$ had different types of other pathology (Table II).

Post-operative pain analysis revealed that six hours after operation mean pain score is significantly higher in open group, $36.45 \pm 10.39$ versus $32.77 \pm 8.72$ $(\mathrm{p}=0.037)$. Required amount of rescue parenteral narcotic analgesia is also significantly higher, 28 versus $14(\mathrm{p}=0.027)$ (Table II).

There were significant differences between the patients in the laparoscopic and open groups regarding time required to tolerate oral fluid $(10.16 \pm 4.15$ hs vs. $12.62 \pm 3.84$ hs, $\mathrm{p}=0.001)$ and normal diet $(18.48 \pm 4.386$ hs vs. $21.93 \pm 6.21 \mathrm{hs}, \mathrm{p}=$ 0.00059 ) (Table II). The overall hospital stay was 29.94 \pm 8.99 hours( range, 24-72 hs) in the LA group and $35.41 \pm 11.3$ hours (range 24-90 hs) in the total open group $(p=0.0039)$ (Table-II).

There were two intra-operative port site bleeding (right lower quadrant port) in the LA group, managed by diathermy coagulation and temporary all coat abdominal wall suture. In three cases in the LA group there was partial avulsion of parietal peritoneum due to use of $10 \mathrm{~mm}$ suprapubic port and forceful introduction. No active measures were taken and all recovered uneventfully. In one patient in the LA group there was per-operative bleeding due to loose ligature and ineffective diathermy coagulation of appendicular artery. The situation tackled effectively by intra-corporeal gauge compression followed by an application of clip. In another cases in OA group accidentally the appendicular artery was slipped and retracted, required wound extension to control the situation. In LA group one patient developed mild surgical emphysema, resolved spontaneously. Wound or port site infection is significantly higher in open group ( $\mathrm{p}=0.019)$. Mortality rate was " 0 " in both groups. No patient in the LA group required conversion to open operation. 
Table-I

\begin{tabular}{|c|c|c|c|}
\hline \multicolumn{4}{|c|}{ Base line characteristics of laparoscopic and open appendicectomy group } \\
\hline & Laparoscopic & Open & $\mathrm{p}$ Value \\
\hline No. of patients & 62 & 58 & \\
\hline Mean age(yrs) & $29.83 \pm 5.2(19-45)$ & $31.05 \pm 6.157(19-49)$ & 0.245 (n.s.) $\dagger$ \\
\hline Male:female & $19: 43$ & $32: 26: 00$ & $0.0058(\mathrm{~s}) \ddagger$ \\
\hline Mean BMI & $23.27 \pm 1.85$ & $23.92 \pm 1.66$ & 0.045 (n.s.) $\dagger$ \\
\hline \multicolumn{4}{|l|}{ ASA class } \\
\hline I & 49 & 50 & 0.3 (n.s.) $\ddagger$ \\
\hline II & 13 & 8 & \\
\hline \multicolumn{4}{|l|}{ No. attack } \\
\hline Single & 16 & 19 & 0.40 (n.s.) $\ddagger$ \\
\hline Multiple & 46 & 39 & \\
\hline WBC preoperative(thousand $/ \mathrm{cmm}$ ) & $11.13 \pm 0.65$ & $11.18 \pm 0.7$ & 0.67 (n.s.) $\dagger$ \\
\hline
\end{tabular}

Values in the parentheses are range. \pm indicates standard deviation; n.s., not significant, s. significant, $\dagger$ student $t$ test, $\downarrow$, chi squre test.

\section{Table II}

Per-operative and post operative Clinical outcomes

\begin{tabular}{|c|c|c|c|}
\hline & Assigned to LA & Assigned to $\mathrm{OA}$ & $\mathrm{p}$ \\
\hline \multicolumn{4}{|l|}{ Mean operation time (min) } \\
\hline Total series & $36.51 \pm 15.81(21-90)$ & $31.62 \pm 19.61(17-107)$ & $0.136($ n.s $) \dagger$ \\
\hline HUR type (no.13:9) & $37.92 \pm 16.28(23-82)$ & $62.55 \pm 20.04(42-107)$ & $0.008(\mathrm{~s}) \dagger$ \\
\hline \multicolumn{4}{|l|}{$(\mathrm{n} .49: 49)$} \\
\hline \multicolumn{4}{|l|}{ Peroperative pathology } \\
\hline Acute appendicitis & 45 & 47 & $0.00421(\mathrm{~s}) \ddagger$ \\
\hline Alternate pathology & 14 & 2 & \\
\hline Normal appendix & 3 & 9 & \\
\hline Histologically normal appendix & $17(37.78 \%)$ & $11(23.4 \%)$ & 0.27391 (n.s) \\
\hline \multicolumn{4}{|l|}{ Post-operative pain score(mm,VAS) } \\
\hline \multicolumn{4}{|l|}{6 hours after operation } \\
\hline 12 hours after operatio & $32.77 \pm 8.72$ & $36.45 \pm 10.39$ & $0.037(\mathrm{~s}) \dagger$ \\
\hline 18 hours after operation & $17.59 \pm 6.88$ & $17.62 \pm 8.68$ & $0.96(\mathrm{n} . \mathrm{s}) \dagger$ \\
\hline $4.45 \pm 6.09$ & $2.72 \pm 6$ & $0.114($ n.s $) \dagger$ & \\
\hline Rescue narcotic analgesia required (no. of patient) & 14 & 28 & $0.027(\mathrm{~s}) \dagger$ \\
\hline Time to liquid(h) & $10.16 \pm 4.15$ & $12.62 \pm 3.84$ & $0.001(\mathrm{~s}) \dagger$ \\
\hline Time to solid(h) & $18.48 \pm 4.386$ & $21.93 \pm 6.21$ & $0.00059(\mathrm{~s}) \dagger$ \\
\hline Hospital stay & $29.94 \pm 8.99$ & $35.41 \pm 11.3$ & $0.0039(\mathrm{~s}) \dagger$ \\
\hline
\end{tabular}




\section{Table-III}

\section{Alternate pathology detected peroperatively}

$\begin{array}{cc}\text { Alternate pathology } & \begin{array}{c}\text { Assigned } \\ \text { to LA }\end{array} \\ \text { to OA }\end{array}$

$\begin{array}{ll}\text { Rt. Ovarian cyst } & 2 \\ \text { PID } & 2 \\ \text { Sulpingitis } & 3 \\ \text { Adhesion } & 4 \\ \text { Ruptured ovarian follicle } & 1 \\ \text { Ruptured luetine cyst } & 2\end{array}$

$\begin{array}{ll}2 & \\ 2 & \\ 3 & \\ 4 & 1 \\ 1 & \\ 2 & 1\end{array}$

Table-IV

\begin{tabular}{lccc}
\multicolumn{2}{c}{ Complications } \\
& $\begin{array}{c}\text { Laparoscopic } \\
\text { group }(\mathrm{n}=62)\end{array}$ & Open group $(\mathrm{n}=58)$ & $\mathrm{P}$ \\
\hline Port site bleeding & 2 & Not applicable & not applicable \\
Parietal peritoneal avulsion & 3 & 1 & \\
Peroperative bleeding & 1 & 9 & \\
Port site infection & 2 & not applicable & \\
Port site erythema & 2 & 0 \\
Subcutaneous Emphysema & 1 & Not applicable & \\
Mortality & 0 & 0 & \\
Conversion to open & &
\end{tabular}

S indicates significant, $€$ Fisher's Exact test.

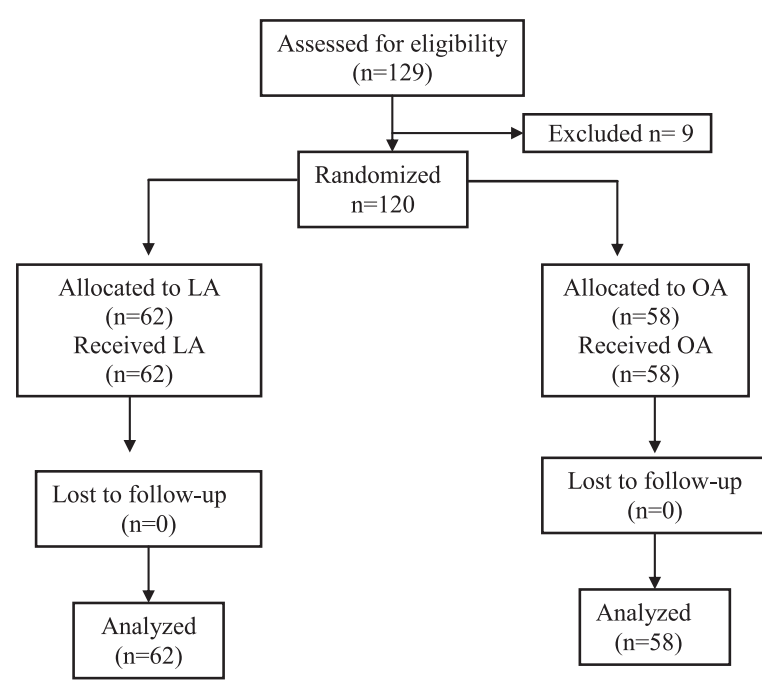

Fig.-1: Flow diagram of trial participants

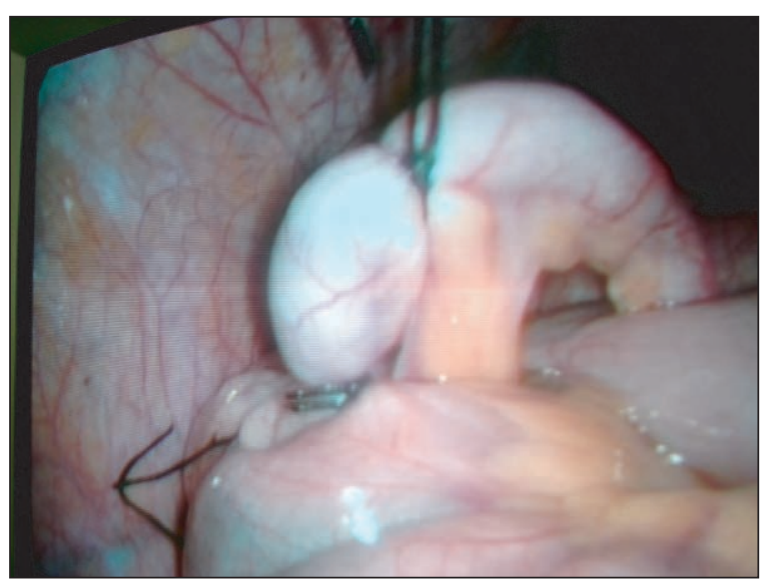

Fig.-2: Shows intracorporeally ligated Appendix base 


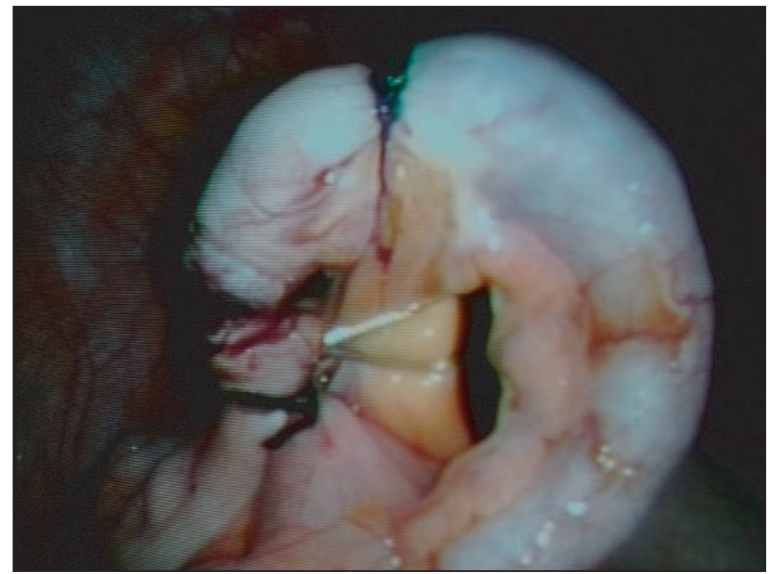

Fig-3: Shows clipping of the mesoappendix

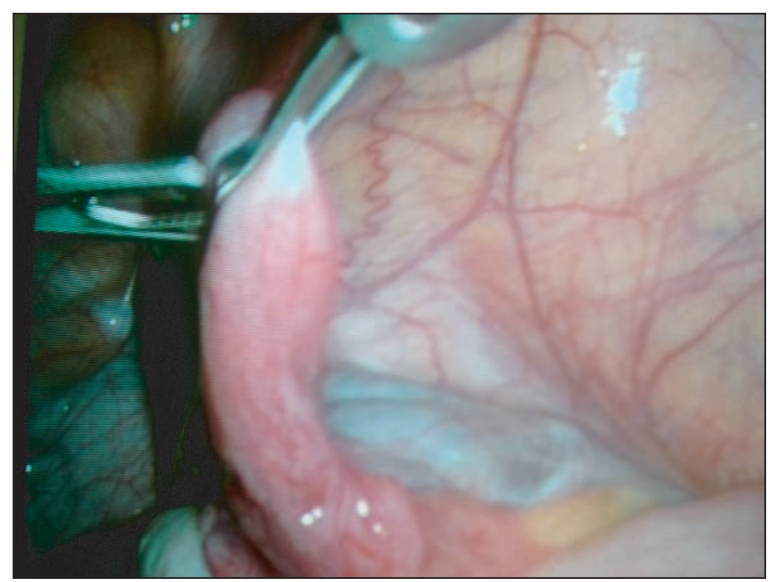

Fig-4: Shows salphingitis as concomitant finding

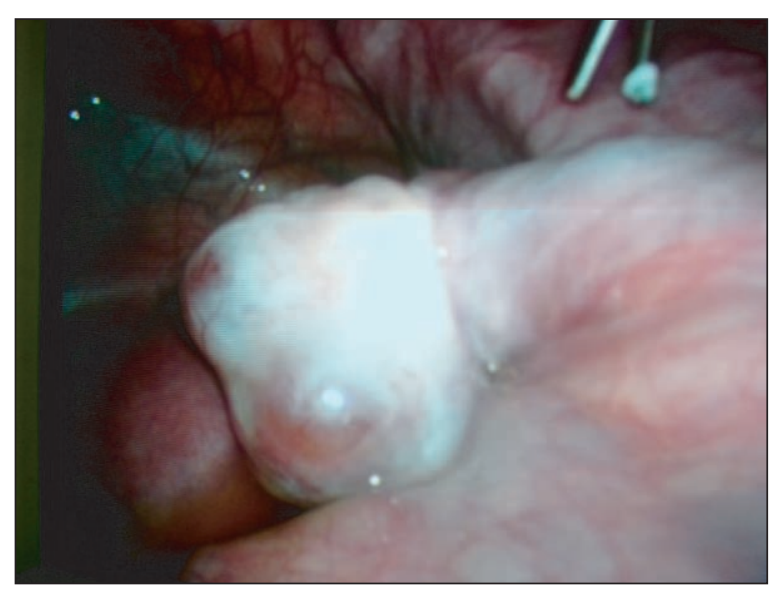

Fig-5: Shows ovarian tumor as concomitant finding

\section{Discussion:}

Laparoscopic Appendicectomy (LA) is relatively a new procedure as compared to laparoscopic Cholecystectomy (LC). A lot of analysis being performed through out the world regarding laparoscopic versus open appendectomy. Unlike LC, LA has not universally accepted as "Gold standard" because of controversy regarding exact benefit.

Despite the high success rate of conventional appendectomy, the most important drawback is negative appendicectomy rate, still in the range of $20 \%$ to $30 \%, 13,14$. The surgical technique for laparoscopic appendectomy is now well described, and several methods have been developed, involve single-port technique ${ }^{15}$, two port ${ }^{16}$ or standard 3- or 4-trocar technique. The base of the appendix can be divided by intra or extracorporeal suturing, endo-loop placement, clip application, stapling device or even without any clip or ligature by bipolar diathermy only ${ }^{17}$.

On the basis of preliminary experience of 47 cases of LA as case series this prospective randomized controlled trial was undertaken to evaluate the time of operation, per-operative findings, concomitant and or other pathologies with negative appendicectomy rate, post operative pain, hospital stay, and incidence of complications.

Base line characteristics in both groups were same except (Table-I) predominant female sex in LA group. This is probably due to more consciousness of female patients regarding cosmatics and less pain explained during taking of informed consent. It may affect the per-operative findings.

The mean operation time in the laparoscopic group is longer (36.51minutes vs.31.62 minutes). But it is not statistically significant $(\mathrm{p}=0.136)$. This is relatively shorter (LA group) than the reported operative time of 40 to 50 minutes in maximum studies. In a Metaanalysis of 23 studies by Omer A et.al ${ }^{18}$ mean operation time varies from 41 to 72 minutes. However present finding is comparable to the result of Utpal $\mathrm{D}^{19}$, found mean operative time of 28 minutes in laparoscopic group. In this study, operation time in laparoscopic and open group is almost same $(36.52 / 31.62 \mathrm{~min})$. In many studies during early nineties operation time in laparoscopic group was 
longer, ( $61 \pm 4.8$ minutes by van $\mathrm{L}$ et.al ${ }^{4}, 87$ minutes by Richard $\mathrm{C}$ et.al ${ }^{20}$ )and also significantly more in comparison to open operation, (61 versus 46 minutes ${ }^{4}, 87$ versus 65 minutes $^{20}$ ). But in almost all recent studies the result failed to show a significant difference ${ }^{18}$, even when it was performed by trainee surgeons $(74 \pm 2.8$ minutes $/ 63 \pm 2.2$ minutes in LA and OA group respectively ${ }^{21}$ ) like present study. This improvement is due to overcoming of learning curve and much technological advancement during last couple of years. In most of the series LA performed by a group of junior surgeons, but in present study the laparoscopic surgery was done by relatively experienced surgeon which might be the cause of relatively lower duration of operation.

When the open and laparoscopic groups are divided into subsets based on position of the appendix, the real advantage of laparoscopic group in terms of operation time become evident. The mean operation time for high up retrocecal (HUR) subset in open group is longer (62.55 minutes vs, 37.92 minutes; $p=0.0083$ ). LA has the advantage to give clear and magnified visions of appendix with more space to maneuver irrespective of its position through a small hole. But in OA incision invariably needs to be extended, which is responsible for more operation time.

In LA group alternate pathology was found in 14 cases and in open group it was $2(p=0.00421)$. There were 3 normal appendix in LA group and 9 in open group. All 17 in laparoscopic group and all 9 in open group were histologically normal appendix. So the negative diagnosis is higher in LA group (37.78\% versus $23.4 \%$ ) though not significant statistically, $p=0.27391$. This is due to removal of normal appendix detected along with concomitant other pathologies. There is strong suspicion that undetected pathology along with normal appendix left out in OA group. Although the treatment of acute appendicitis is simple and straightforward, its diagnosis remains a challenge, and the negative appendectomy rate in large series ranges from $15 \%$ to $33 \%{ }^{6}$. The incidence of perforated appendicitis in delayed cases is not less then $14 \%^{22}$. The risk of two adverse outcomes, misdiagnosis and perforation of appendix must be balanced. Ultrasonography (US), CT scan and diagnostic laparoscopy as a method of investigation applied to reduce the incidence of negative or misdiagnosis. The positive predictive value for $\mathrm{CT}$ is $83.8 \%$, and for US is $81.3 \%$. The false-negative rates are $60 \%$ for CT and $76.1 \%$ for $\mathrm{US}^{6}$. In single port laparoscopy the appendix could only be visualized directly in as high as 10-34 \% of $\operatorname{cases}^{20}$. The LA gives an opportunity to expose the whole abdomen without any extra effort facilitates alternate left out pathology, is the cause of high incidence of misdiagnosis in open appendicectomy. We performed appendicectomy in all cases. To do or not to do appendicectomy in case of detected alternate pathology or in normal appendix is a debate. Van LV et.al $^{4}$ suggested to do the appendicectomy if the detected pathology does not contraindicates appendicectomy. In another study by Steven LL et.al ${ }^{6}$ appendicectomy were performed in all cases as incidental appendicectomy. In present study detected alternate pathology was managed laparoscopically either by the operating surgeon or with the help of gynaecological surgeons as demanded.

Post-operative pain 6 hours after operation is significantly low in laparoscopic group $(32.77 \pm 8.72 \mathrm{~mm}$ versus $36.45 \pm 10.39, \mathrm{p}=0.037)$ and rescue narcotic analgesia required in open group is significantly high (in 28 cases versus 14 cases, $p=$ 0.027 ) .But after 6 hours pain score is same in both groups. During open operation muscle splitting is responsible for more pain. The present result is comparable to the result of Van LV et.al ${ }^{4}$, though their result was marginally insignificant $(p=0.06)$ and study by Mustafa $\mathrm{K}^{23}$. A prospective randomized trial of 75 by Richard CF et.al ${ }^{20}$ detected shorter duration of parenteral and oral analgesic use in laparoscopic group $(\mathrm{p}<0.05)$. But Namir $\mathrm{K}$ et.al ${ }^{24}$ detected no difference of pain score between open and laparoscopic group even in early post-operative period.

Time to both liquid and solid is significantly lower in laparoscopic group (Table-III) are consistent with many studies ${ }^{4,5,14,20,24}$. In laparoscopic surgery gut are not exposed to the external environment, there are minimum handling, are the cause of minimum impairment of gut function.

Hospital stay is significantly low in LA group (29.94 \pm 8.99 hs versus $35.41 \pm 11.3, p=0.0039)$. The 
length of hospital stay in present study is short, is similar to many others studies ${ }^{10,18,23,24}$. Few publications, particularly in the early nineties demonstrated hospital stay $>2$ days ${ }^{4,20}$. Perhaps this is one area where OA has caught up with the laparoscopic techniques. Duration of hospitalization from time of operation to discharge of patient was calculated. Prolonged hospitalization is an important factor and peoples ${ }^{25}$ tried to evaluate the factors responsible for prolonged hospitalization after LA which are, nausea and vomiting, leukocytosis, gangrenous or perforated appendicitis and appendix position. Peroperative ondenosation was found as antiemitic routinely in all cases and only few number of patient required narcotic analgesia post-operatively may be the cause of very short hospital stay.

Overall complication and "0" mortality shown in Table IV are comparable to many studies $4,14,19,20,24$. Significantly low incidence of wound infection in LA $(p=0.019)$ is one the most important point in favor of LA. In LA appendix always removed in canula sheath or endo-bag. There is no question of contamination of wound. But in OA what ever may be the level of care always there is chance of wound contamination. A study of 175 LA by et.al ${ }^{14}$ is comparable, though the study showed increased incidence of intraabdominal abscess in laparoscopic group (LA 1.8\%, OA.0.61\%). But the complication was limited to gangrenous or perforated appendicitis and probably was related to vigorous irrigation of the peritoneal cavity.

In present study no patient in the LA group required conversion to open. It is consistent with very low conversion rate ranging from $0.6-2 \%$ even some times in a hand of trainee's ${ }^{26,27,28}$. There were high conversion rate $(2-12 \%)$ in study done during early nineties $4,20,29$. In comparison to laparoscopic Cholecystectomy LA gained its acceptability very slowly due to many similar results both in open and laparoscopic technique. In many series operation were performed by junior surgical team may be cause of high conversion rate. The" 0 " mortality of the study consistent with many studies $4,5,20,21,24$.

Present study has some limitations. Cost and quality of life after operation were not analysed. Follow-up was limited to the first 1 week postoperatively. The aim was to detect operation time, pain after operation, concomitant findings and or negative exploration, early postoperative complications after hospital discharge.

\section{Conclusion:}

The study has clearly demonstrated that the operation time in laparoscopic group is though insignificantly high but it is significantly low when high-up retrocaecal group are analyzed separately. The laparoscopic technique provide an opportunity to detect concomitant pathology in the lower abdomen easily without any extra effort and thereby reduces real negative appendicectomy rate.

Pain score is significantly low in LA group during 6 hours after operation, and required dose of narcotic analgesia is more in OA group though it becomes similar after 6 hours. Laparoscopic group tolerated oral fluid and diet early and hospital stay is significantly low in LA group.

This study confirmed the benefits of laparoscopic appendicectomy over open operation. So it is concluded that laparoscopic appendicectomy should the procedure of choice.

\section{Acknowledgements:}

The authors thank Dr Subroto Barua and Dr Wahed for helping data collection, and Professor Gofranul Hoque, Professor P C Barua and Professor Abdus Salek Molla for contributing to design and the editing of the paper. This study was funded by a research grant from Ministry of Health and Family Welfare, the Govt. of Peoples Republic of Bangladesh.

\section{References:}

1. McBurney $\mathrm{C}$. The incision made in the abdominal wall in cases of appendicitis, with a description of a new method of operating. Ann Surg. 1894; 20: 38.

2. Samelson SL, Reyes HM. Management of perforated appendicitis in children-revisited. Arch Surg. 1987; 122: 691-696.

3. Editorial. A sound approach to the diagnosis of acute appendicitis. Lancet. 1987; i: 198-200.

4. Van LV, Jose MV. Laparoscopic Versus Conventional Appendicectomy. Ann Surg.1993;218(5):685-692.

5. Nana AM, Ouandji CN, Simoens C, Smets D, Mendes da Costa P. Laparoscopic appendectomies: results of a monocentric prospective and non-randomized study. Hepatogastroenterology. 2007: Jun;54(76):1146-52. 
6. Steven LL, Alicia JW, Hung SH. Computed Tomography and Ultrasonography do not improve and may delay the diagnosis and treatment of acute appendicitis. Arch Surg. 2001;136:556-562.

7. Whitwort CM, Whitwort PW,Sanfillipo J, Polk HC. Value of diagnostic laparoscopy in young women with possible appendicitis. Surg Gynecol Obstet. 1988; 167:187-190.

8. Semm K. Endoscopic appendectomy. Endoscopy. 1983; 15: 59-64.

9. Long KH, Bannon MP, Zietlow SP, et al. A prospective randomized comparison of laparoscopic appendectomy with open appendectomy: clinical and economic analyses. Surgery. 2001; 129: 390-400.

10. Martin LC, Puente I, Sosa JL, Bassin A, Breslaw R, McKenney MG, Ginzburg E, Sleeman D. Open versus laparoscopic appendectomy. A prospective randomized. Ann Surg. 1995 September; 222(3): 256-262.

11. Guller LU, Hervey S, Purves H, Lawrence H. Versus Open Appendectomy: Outcomes Comparison Based on a Large Administrative Database. Ann Surg. 2004:239(1):43-52.

12. Lord B, Parsell B: Measurement of pain in the prehospital setting using a visual analogue scale.Prehosp Disast Med 2003;18(4):353-358.

13. David RF, Arden M, Thomas K, Patchen D. Has Misdiagnosis of Appendicitis Decreased Over Time ? JAMA. 2001;1748-1753.

14. Rohit G, Cliff S, Fahad B, Daniel W. Infectious complications following laparoscopic appendectomy.Can J Surg. 2006: 49(6):397-400.

15. Ates O, Hakgiider G, Olguner M, Akgiir FM. Single-port laparoscopic appendectomy conducted intracorcoreally with the aid of a transabdominal sling suture. J Pediatr Surg. 2007: Jun, 42(6):1071-4.

16. Konstadoulakis MM, Gomatos IP, Antonakis PT, Manouras A, Albanopoulos K, Nikitear N, Leandros E, Bramis J. Twotrocar laparoscopic-assisted appendectomy versus conventional laparoscopic appendectomy in patients with acute appendicitis. J Laparoendosc Ady Surg Tech A. 2006 Feb,6(1):27-32.

17. Khanna S, Khurana S, Vij S. No clip, no ligature laparoscopic appendectomy. Surg Laparosc Endosc Percutan Tech. 2004:14(4):201-3 (Abs).
18. Omer A, Thanos A, Paris P, Sanjay P, James H, Vitali M, Paraskevas P, Ara D. Laparoscopic Versus Open Appendicectomy in children- A Meta-Analysis. Ann Surg. 2006: January, 243(1):17-27.

19. Utpal D.Laparoscopic versus open appendectomy in west Bengal,India. Chinese Journal of Digestive Disease. 2005:6(4): 165-169.

20. Richard CF, John WR, Richard ES, Samuel KS, John CH, Randall WS, Monford DC,Blake H. A prospective Randomized trial Comparing Open Versus Laparoscopic Appendectomy. Ann Surg.1994:219(6):725-731.

21. Kenneth W, Tristram D, Andrew P. Unsupervised Laparoscic Appendicectomy by Surgical Trainees is safe and Time-effective. Asian J Surg. 2007:30(3):161-6.

22. Omundsen M, Dennett E. Delay to appendicectomy and associated morbidity: a retrospective rewiew. ANZ J Surg. 2006: Mar, 76(3):153-5.

23. Mutafa K, Khalid HQ. Laparoscopic versus open appendectomy.Pakistan J.Med.Res. 2003:43(1),15-9.

24. Namir K, Rodney JM, ShirinT, Anna G, Rahila E. Laparoscopic versus Open Appendectomy A Prospective Randomized Double-Blind Study. Ann Surg.2005:Sep, 242(3):439-450.

25. Amaral PC, Filho EM, Galvao TD, Junior EE, Magalhaes, GE, Mascarenhas F, Fahel E. Factors leading to long-term hospitalization after laparoscopic appendectomy. JSLS. 2006: Jul-Sep;10(3):355-8

26. SaiPrasad TR, Chui CH, Jacobsen AS. Laparoscopic appendicectomy in children: A trainee's perspective. Ann Acad Med Singapore. 2006:Oct,35(10):694-7.

27. Yau KK, Siu WT, Tang CN, Yang GP, Li MK. Laparoscopic versus open appendectomy for complicated appendicitis. J Am Coll Surg. 2007: Jul,205(1):60-5.

28. Muller M, Terzie A, Rodehorst A, Mahfouz M, Bottger T Laparoscopic appendectomy as training procedure for all stages of appendicitis. Zentralb Chir. 2007: Feb, 132(1)10-5 (Abstract).

29. Larry CM, Ivan P, Jorge LS, Alan BRalph B, Mark GM, Enrique G, Danny S. Open Versus Laparoscopic Appendectomy-a Prospective Randomized Comparison. Ann Surg. 1995:222(3):256-262. 